\title{
Farias Brito e a crise da modernidade
}

\author{
Farias Brito and the crisis of modernity
}

DOI: https://doi.org/10.20873/rpv6n1-83

\author{
Francisco José da Silva \\ Orcid: https://orcid.org/0000-0001-5342-2280 \\ Email: franz.silva@ufca.edu.br
}

\begin{abstract}
Resumo
0 presente artigo parte da discussão sobre a questão da Modernidade, tendo como referência a crítica do filósofo Raimundo Farias Brito (1862-1917) que aponta a crise moderna e a incapacidade das correntes filosóficas europeias do Positivismo (Comte), do Evolucionismo (Spencer) e do Socialismo (Marx) em dar uma resposta satisfatória a tal situação de relativismo, ceticismo e ausência de um princípio unificador. A proposta britiana passa pela retomada da Metafísica, numa abordagem naturalista, em vista de uma nova concepção de Religião que pudesse garantir a unidade e coesão social.
\end{abstract}

\section{Palavras-chave}

Modernidade. Crise. Crítica. Farias Brito.

\begin{abstract}
The present article starts from the discussion on the question of Modernity, having as reference the critic of the philosopher Raimundo Farias Brito (1862-1917) that points to the modern crisis and the inability of the European philosophical currents of Positivism (Comte), Evolutionism (Spencer) and Socialism (Marx) to give a satisfactory answer to such situation of relativism, skepticism and absence of a unifying principle. The britian proposal involves the resumption of metaphysics, in a naturalistic approach in view of a new conception of Religion that could guarantee unity and social cohesion.
\end{abstract}

\section{Key-words}

Modernity. Crisis. Critic. Farias Brito. 


\section{Introdução}

A temática do Colóquio "A Modernidade e seus intérpretes" traz à tona dois problemas fundamentais no que diz respeito à modernidade como pensada pela filosofia, em primeiro lugar, o estatuto da modernidade em si mesma, como época de transformações que marcaram o mundo tal como o conhecemos hoje, em segundo lugar, a maneira como este legado moderno tem sido compreendido, interpretado e avaliado por seus intérpretes. Neste sentido, devemos considerar não apenas as perspectivas dos autores modernos europeus sobre essa época, mas ampliar o olhar de forma crítica, a partir da contribuição de pensadores que estão à margem desta mesma tradição europeia.

A modernidade tornou-se um problema filosófico na medida em que as transformações por ela trazidas estão marcadas pelo signo do paradoxo, ou seja, ela foi uma época de avanços na ciência e na técnica, refletidos pela filosofia, mas ao mesmo tempo uma época de avanço do capitalismo, da exploração do trabalho e das desigualdades, além das conquistas coloniais, da colonização predatória, do epistemicídio das tradições ancestrais e dos conflitos religiosos.

Segundo Manfredo Oliveira,

A modernidade, sua significação e sua contribuição para a antropogênese estão de novo em debate. A crise cultural que vivemos é crise contra a razão, contra a ilustração, numa palavra contra a modernidade. A crítica da razão instrumental desenvolvida pela modernidade desemboca numa crítica à modernidade enquanto tal, e, em última análise, numa crítica à própria razão, que é vista como instrumento de repressão (OLIVEIRA, 1989, p. 7).

No que diz respeito aos intérpretes da modernidade, encontramos as mais diversas análises e perspectivas, seja de uma retomada do projeto da modernidade como uma época de esclarecimento e emancipação (HABERMAS, 1990), seja como sua crítica radical e a crise que foi por ela instaurada e precisa ser superada, neste sentido, há aqueles que defendem uma 
despedida absoluta da modernidade (pós-modernidade) ${ }^{1}$, outros sua superação e ultrapassamento (transmodernidade) (DUSSEL, 1993). A crise da modernidade carrega essa ambiguidade de ser ao mesmo tempo a conservação de um projeto ou a superação do mesmo, por meio de outro totalmente distinto, nos quais a própria filosofia se vê implicada em seu estatuto e em sua substância. Resta aos filósofos contemporâneos tomar posição diante desse dilema que se apresenta e envolve os grandes temas da tradição filosófica, tais como a epistemologia, a teoria do conhecimento, a ética, a política e a estética, buscando uma saída desse impasse a respeito do legado da modernidade.

\section{Farias Brito e a Filosofia do Brasil}

Para refletir esse problema que é a modernidade e sua interpretação, pretendemos seguir um caminho que parte de uma visão de certo modo extrínseca ao pensamento europeu, que embora seja por ele influenciado e reflita suas questões, busca tomar uma posição crítica e distinta em seu enfrentamento destes problemas. Referimo-nos ao pensamento elaborado no Brasil entre o final do século XIX e início do século XX, em especial por um pensador que pode ser considerado um outsider dentro da própria tradição a que pertence, tratamos aqui do pensamento do filósofo cearense Raimundo de Farias Brito (1862-1917), o qual, como crítico dos movimentos filosóficos no Brasil de sua época, amplia sua crítica à própria modernidade enquanto tal, como uma época de crise e anarquia, que pretende superar em seu sistema teleológico naturalista, amparado numa racionalidade eivada de espiritualismo.

Farias Brito nasce no período da segunda metade do século XIX, quando o Brasil havia saído recentemente do conflito da Guerra do Paraguai (1864-1870), quando vemos o país confrontando-se consigo mesmo, com suas mazelas, sua tradição colonial e escravista, que se vê agora abalada pelo influxo de ideias modernizantes e republicanas. Nosso filósofo se encontra em um momento de profundo debate filosófico no Brasil (formou-se bacharel em 1884),

\footnotetext{
${ }^{1}$ O filósofo italiano Gianni Vattimo, em sua obra $O$ Fim da Modernidade, apresenta as características da chamada pós-modernidade, como ultrapassagem da modernidade, da ideia de progresso e das grandes narrativas (cristianismo, iluminismo, marxismo) numa época onde predomina o niilismo. Cf. VATTIMO, 1996; ainda sobre o conceito de pós-modernidade veja-se as obras de LYOTARD, 1996.
} 
quando se digladiam as ideias conservadoras e progressistas, representadas pelos movimentos filosóficos do ecletismo ${ }^{2}$, positivismo ${ }^{3}$ e evolucionismo ${ }^{4}$, que tiveram como lugar de (des)encontro a Faculdade de Direito do Recife, centro intelectual que ficou conhecido como o movimento Escola do Recife ${ }^{5}$. A Escola do Recife foi onde o filósofo cearense estudou na segunda metade do século XIX, lá foi profundamente influenciado pelo pensador sergipano Tobias Barreto (1839-1889), especialmente em sua crítica ao positivismo e em relação à tomada de posição diante das polêmicas intelectuais, que serviram de inspiração para pensar os problemas nacionais, como também podemos perceber na reflexão do filosofo sergipano Silvio Romero (1851-1914), em suas obras A Filosofia no Brasil (1878) e Doutrina contra doutrina (1894) (R0MERO, 2001).

Segundo o filósofo sergipano, ao falar sobre a filosofia no Brasil,

Os filósofos brasileiros não se prestam, repito, a uma classificação lógica, filha das leis que presidem ao desenvolvimento dos sistemas, não existindo esses aqui. Forçado a apresentar uma, ela seria em três grupos: escritores educados sob o regime sensualista metafísico francês dos primeiros anos deste século e que passaram para o ecletismo cousiniano; b) reatores neocatólicos filiados as doutrinas de Gioberti e Rosmini, ou às de Balmés e Ventura; c) e afinal os espíritos que se vão emancipando sob a tutela das ideias de Comte ou as de Darwin. (ROMERO, p. 36-37).

Farias Brito é um caso especial, uma vez que, apesar de formado na Escola do Recife sob a influência de Tobias Barreto (sendo um crítico do positivismo como este), o qual havia afirmado peremptoriamente “a Metafisica está morta!" (PAIM, 1966, p. 45), assumiu uma postura independente em relação aos movimentos de sua época, retomando justamente as questões da Metafisica, da reflexão sobre a consciência, a finalidade do mundo e o Absoluto. Em sua obra, o filósofo cearense, apesar de ser um profundo leitor do pensamento antigo ${ }^{6}$, se vê estreitamente vinculado ao pensamento moderno, principalmente em razão dos debates acalorados que

\footnotetext{
${ }^{2}$ Uma posição intermediaria que pretendia conciliar as ideias antagônicas dos principais sistemas filosóficos modernos, buscando uma síntese do que havia de verdadeiro em que cada um deles. 0 fundador do ecletismo filosófico é o francês Victor Cousin (1792-1867).

${ }^{3}$ Sobre o Positivismo e suas principais ideias sobre a filosofia e a ciência, conferir a obra de COMTE, 1983.

${ }^{4}$ Em relação ao Evolucionismo, destacamos o pensamento de Ernst Haeckel. Cf. HAECKEL, 1947.

${ }^{5}$ Sobre a Escola do Recife, seu impacto e seus pensadores, confira-se: PAIM, 1966; NOGUEIRA, 1980.

6 Vale lembrar as referências a Sócrates (no início e fim de sua obra), nas citações de Platão e suas pesquisas sobre os Fenícios e Hebreus.
} 
vivenciou na Escola do Recife, mas como poderemos constatar, numa perspectiva crítica ao legado da modernidade.

Essa relação ambígua de herança e oposição ao pensamento moderno, podemos constatar em sua obra magna, A Finalidade do Mundo (1895-1905), escrita em três volumes densos e articulados, que pretendia ser uma apresentação de sua concepção de Filosofia (enquanto atividade permanente do espírito) no primeiro volume, bem como uma crítica da modernidade (no segundo), e a fundamentação de sua teleologia naturalista, no terceiro ( $A$ Finalidade do Mundo Prefácio a 1aedição). Veremos então em que sentido Farias Brito se posiciona em relação ao que ele denomina de "crise moderna".

\section{A crise da modernidade segundo Farias Brito}

No final do século XIX, Farias Brito se via então completamente absorvido pela realização de sua obra máxima de teleologia naturalista, como ele mesmo resume no Prefácio de 1895, "tudo em minha vida está subordinado a esse pensamento", cujo objetivo era apresentar em uma ideia central a teoria da finalidade do mundo, a compreensão de Deus, como fundamento da consciência e do real, segundo um mesmo método e plano de ideias, em confronto com o pensamento moderno e a anarquia conceitual e social que dele deriva.

Neste sentido, o volume primeiro trata da filosofia "como atividade permanente do espírito" (BRITO, 2012a), em relação profunda com a ciência e com a moral, tendo como conclusão uma religião naturalista (em oposição ao ateísmo e ao materialismo) que serviria de elemento de coesão social (face a anarquia reinante), mas ao contrário do que se pode pensar, nosso filósofo não pretendia resgatar uma religião dogmática ou mesmo uma ciência positivista em seu sistema.

Em sua definição primeira,

A Filosofia é a fonte comum onde encontram sua justificação os princípios fundamentais de todas as outras ciências, que nestas condições dependem dela. Ou mais precisamente ainda: a filosofia é o conhecimento universal. É assim que o verdadeiro caráter da filosofia em suas relações com as ciências só pode ser determinado por meio de imagens como estas: A filosofia é uma árvore; as ciências são ramos mais ou menos frondosos que brotam desta árvore, o fruto que ela produz. (...) Penso assim: a ciência é o conhecimento já feito, o conhecimento organizado e verificado; a filosofia é o conhecimento em vias de formação" (BRITO, 2012a, p. 17). 
Após discorrer longamente sobre o estatuto da Filosofia, sua relação com as ciências, o direito, a moral, a estética e a religião, fica patente no decorrer de sua obra o confronto direto com a modernidade e com seus principais sistemas do pensamento, deixando claro sua ousadia de não ficar reduzido a mero comentador das obras do pensamento estrangeiro, mas dialogar criticamente com seus interlocutores, buscando uma superação dos impasses gestados pelo próprio pensamento moderno. Neste sentido, o julgamento que faz em relação à modernidade é severo e bastante incisivo, ao reconhecer certo fracasso no projeto moderno. Percebemos assim a originalidade e o desafio imposto a si mesmo pelo filósofo cearense, concentrando suas forças num projeto sistemático dos mais autênticos em nossa tradição.

Segundo o filósofo,

em verdade, a obra do pensamento moderno é como um vasto incêndio, que tudo inflama e devora, nada escapa a sua fúria indomável, sopra com a mesma força no alto e no baixo (...) e da destruição e demolição que promove especialmente contra a religião e a teologia pode-se dizer que não fica pedra sobre pedra (BRITO, 2012a, p. 219-220).

Essa sanha devastadora do pensamento moderno conduz a impasses sem resolução tanto no âmbito do conhecimento, quanto no da práxis, o que seria uma das razões pelas quais nos encontramos em uma época de anomia e anarquia. 0 espírito humano jaz em uma decadência cultural, onde impera o ceticismo e o pessimismo. 0 conflito entre fé e razão, ou revelação e convicção é um dos principais problemas nos quais está enredada a humanidade moderna. Neste ponto, vale lembrar que em alguns pontos essa também foi a crítica feita pelo filósofo francês Augusto Comte à condição da humanidade no que diz respeito a sua situação no âmbito do conhecimento (marcado pela coexistência de concepções teológicas e metafisicas ultrapassadas) e da vida em sociedade (eivada de conflitos sociais e de classes) ${ }^{7}$, muito embora a proposta apresentada pelo francês, ou seja, o Positivismo e seu cientificismo anti-metafísico, seja justamente uma das concepções mais criticadas pelo cearense.

Ainda sobre o resultado da crítica moderna, nos esclarece o filósofo,

\footnotetext{
${ }^{7}$ Comte em sua filosofia positiva também concebia uma ideia que agregava os princípios de ordem, progresso e amor, como fundamentos da sociedade, nisso podemos perceber a influência do lema positivista na bandeira do Brasil. Sobre o Positivismo e sua presença no Brasil, veja-se LINS, 1964.
} 
Assim, pode-se estabelecer como resultado geral e definitivo da crítica moderna: $1^{\circ}$ ) que nada permanece de pé do que nos legou o passado, mas também: $2^{\circ}$ ) que a obra do futuro está ainda inteira por fazer-se. Daí o resultado caótico do espírito humano esmagado pelo peso da dor na ausência absoluta de convicções com que possa fortificar-se para reagir e lutar; daí o estado de perturbação e desordem a que se acham reduzidos todos os povos e todas as instituições, faltando aos homens garantia e justiça, faltando as sociedades coesão e estabilidade, daí o pessimismo, a confusão, a anarquia (BRITO, 2012a, p. 238).

No segundo volume de A Finalidade do Mundo (cujo subtítulo é Filosofia moderna), Farias Brito desenvolve uma análise crítica da filosofia moderna, passando em revista os principais sistemas de pensamento (filosofia dogmática - empirismo, racionalismo, Spinoza, e, filosofia da associação - Stuart Mill, Spencer), num elaborado trabalho de hermenêutica histórica e crítica da modernidade. Neste volume, o ponto de partida está na questão da fundamentação de um conhecimento sobre o Universo, sobre Deus e a alma humana, os quais tinham sido objeto da tradição filosófica desde suas origens, mas que na modernidade acaba por se dividir em duas abordagens principais, o idealismo e o realismo (BRIT0, 2012b, p. 15).

O filósofo, após reconhecer o fracasso do edifício moderno no que diz respeito à resolução dos problemas metafísicos e dos conflitos sociais, tendo como resultado um rastro de sofrimento e sangue, que tem seus inicios com o Papado, passando pelo absolutismo e pela derrocada da democracia e da revolução francesa (1789), se detém especialmente em três sistemas que pretendiam dar uma resposta a esses problemas, fazendo uma análise e uma crítica dos mesmos, são eles: a) a "ditadura científica" de Augusto Comte, b) o organicismo individualista de Herbert Spencer, e, c) o socialismo coletivista de Marx (BRITO, 2012b, p. 21).

O Positivismo, criado por Augusto Comte, pretendia resolver o conflito epistemológico e a desordem social que se apresentava na modernidade através de uma concepção unitária do saber, chamada filosofia positiva, fundada numa visão cientificista, anti-teológica e anti-metafísica. Uma das grandes contribuições do Positivismo foi a sistematização das ciências (ditas positivas) e a elaboração de uma ciência nova, a chamada física social ou sociologia. O Positivismo teve ampla aceitação no Brasil, sob a liderança de Miguel Lemos (1854-1917) e Raimundo Teixeira Mendes (1855-1927). Em 1876 fundou-se a primeira sociedade positivista do Brasil, tendo à frente os pensadores acima citados com a participação de Benjamin Constant (1836-1891), servindo como ideologia ligada aos interesses dos grupos políticos e militares, 
chegando inclusive a instituir em nosso país o Apostolado Positivista do Brasil e a chamada Igreja Positivista com sua pretensão a uma religião secular (Religião da Humanidade) baseada no legado da arte e na ciência ${ }^{8}$.

Para Farias Brito, o Positivismo é um seco ateísmo que exclui a alma, deixando-se dominar pela impiedade moderna. Assim, nega a ordem do universo e suprime a razão do mundo (BRIT0, 2012b, p. 22). Desta forma, a sociedade sucumbe à condição de máquina sob o domínio da força e om ais cego e feroz absolutismo, tal é a consequência lógica do Positivismo (Idem). 0 Positivismo é, como disse Farias Brito, uma "religião sem Deus", pois nega Deus, mas sustenta a necessidade fundamental da religião.

A filosofia evolucionista de Spencer será a segunda concepção filosófica analisada por Farias Brito. Para ele, a teoria naturalista (individualismo organicista) de Spencer não passa de mera especulação filosófica (BRITO, 2012b, p.24), para explicar a sociedade análoga a um organismo. As ordens econômica e política são comparadas as funções orgânicas e processos. Há, segundo Spencer, na sociedade como no indivíduo um aparelho de produção, distribuição, regulador representado pelo governo. Superorganismo é a compreensão da ordem social, mas isso não passa de especulação sem eficácia pratica, incapaz de servir de base para a reorganização geral e fundamental da sociedade (BRITO, 2012b, p. 26), sem conseguir influência alguma sobre os governos, sendo qualificada por Tobias Barreto como "uma aspiração tão elevada, quanto pouco realizável" (Idem).

Por fim, o filósofo cearense faz sua crítica do socialismo de Karl Marx, definido como uma entre as inúmeras seitas do socialismo moderno, sendo o que alcançou maiores proporções e autoridade (BRITO, 2012b, p. 27), como um complemento de Darwin e Spencer, mas que na verdade se opõe ao individualismo spenceriano absorvido pela atividade social do Estado. Para Farias Brito, o coletivismo é uma concepção de filosofia social que se baseia nas necessidades materiais da sociedade, tudo depende da ordem econômica, a sociedade divide-se nas classes burguesa e proletária, sendo necessária a destruição total desse sistema de exploração.

\footnotetext{
${ }^{8}$ Essa abordagem sobre a religião da humanidade com seu fundamento, dogma, culto e regime podem ser conferidos em COMTE, 1983.
} 
O filósofo cearense coloca em oposição Marx e Bakunin em relação a visão sobre o lugar do Estado, bem como tece sua crítica ao anarquismo como princípio. Dito isto, o filósofo aponta três consequências: 1. A posse do poder, 2. 0 dogma da igualdade e fraternidade, 3. Completase a filosofia da história. 0 programa do socialismo é a destruição sem nada apresentar para a construção (BRITO, 2012b, p. 34). O socialismo é um materialismo que vê o mundo como uma máquina, onde impera o princípio do interesse, sob o domínio da força (Idem).

Por fim, após sua crítica da modernidade em geral e dos três sistemas de pensamento do Positivismo, do Evolucionismo e do Coletivismo marxista, o filósofo cearense apresenta seu ponto de vista a respeito da modernidade, nos seguintes termos,

O meu ponto de vista é: a questão social deve ser resolvida religiosamente, em nome de uma ideia. Uma grande ideia, um grande princípio moral - eis, pois, qual deve ser o ponto de partida para a reforma das sociedades, reforma sobretudo nos caracteres, reforma sobretudo moral. Onde é, porém, que deve ser procurado esse princípio? A resposta só pode ser esta: na filosofia. E efetivamente é só pela filosofia que poderão ser resolvidas as dificuldades da civilização contemporânea. Foi o que eu compreendi; e foi por que esta compreensão terminou por se transformar em convicção profunda e insuperável que tomei a resolução de escrever esta obra, concorrendo assim também com minha pequena pedra para a construção do edifício do futuro (BRITO, 2012b, p. 47).

A resposta de Farias Brito para a crise da modernidade é uma resposta fundada numa concepção religiosa que tem na filosofia seu fundamento, e não numa forma de religião dogmática qualquer. 0 filósofo cearense parte, segundo ele mesmo afirma, de um "fato positivo e real", que se coloca em contraposição ao ceticismo intransigente do espírito moderno. Este fato é a existência do mundo. A Natureza se apresenta para nós de forma evidente aos sentidos e empiricamente dada, ela é em sua estrutura e forma essencial sempre a mesma, inalterável e eterna. Diante desta manifestação da Natureza, surge a questão sobre sua finalidade, para que existe o mundo? Segundo Farias Brito, esta é a questão fundamental, a qual ele dedicou sua vida e cuja solução refletirá na compreensão de nosso próprio destino e na dedução das leis de nossa conduta. 


\section{Considerações finais}

Farias Brito é um dos grandes pensadores brasileiros, cuja ousadia de pensar por si e debater com a filosofia brasileira e europeia de seu tempo, permanece como uma inspiração e um estimulo para todos nós. Sua obra merece destaque e deve ser lida por nós como modelo de itinerário filosófico, uma vez que não se reduziu a mero comentário do que se fazia na filosofia estrangeira, mas um desafio levado corajosamente por ele como um projeto que consumiu toda sua vida.

A crítica de Farias Brito à modernidade, a partir da análise dos sistemas que pretendiam dar uma resposta aos grandes desafios desta época, aponta as limitações e os equívocos destes projetos, uma vez que não conseguiram vislumbrar o verdadeiro cerne do problema do conhecimento que não se reduz ao saber empírico, mas se dirige ao absoluto, e a fundamentação da moral e política para uma sociedade em constantes conflitos sociais e de classe. A proposta do filósofo cearense nos alerta para a necessidade de resgatar o problema de Deus, em seu viés metafisico e religioso como núcleo de todo esse processo.

Entre os grandes méritos que devemos reconhecer em A Finalidade do Mundo, está o de levar a cabo uma crítica da modernidade fundamentada numa leitura metódica e profunda, com um projeto seguido rigorosamente em seu plano, neste sentido, podemos considerar que o projeto britiano exitoso ao perfazer todo o caminho pretendido e apresentar um resultado final, uma metafisica teleológica naturalista.

\section{Referências bibliográficas}

BRITO, R. Farias de. A Finalidade do Mundo - Estudos de filosofia e teleologia naturalista (Vol. I). Brasília: Senado Federal, Conselho Editorial, 2012a.

BRITO, R. Farias de. A Finalidade do Mundo - Estudos de filosofia e teleologia naturalista (Vol. II). Brasília: Senado Federal, Conselho editorial, 2012b.

BRITO, R. Farias de. A Finalidade do Mundo - Estudos de filosofia e teleologia naturalista (Vol. III). Brasília: Senado Federal, Conselho editorial, 2012c.

BRITO, R. Farias de. Trechos escolhidos. Rio de Janeiro: Agir, 1967.

COMTE, A. Curso de Filosofia Positiva. Trad. J. A. Giannotti e M. Lemos. São Paulo: Abril Cultural, 1983.

DUSSEL, E. 1492 - 0 encobrimento do outro (A origem do "mito da modernidade"). Petrópolis: Vozes, 1993. 
JAIME, J. História da Filosofia no Brasil. Petrópolis: Vozes, 1997.

HABERMAS, J. 0 discurso filosófico da modernidade. Lisboa: Dom Quixote, 1990.

HAECKEL, E. O Monismo. Laço entre a religião e a ciência. Lisboa: Lello e Irmãos, 1947.

LINS, I. História do Positivismo no Brasil. São Paulo: Nacional, 1964.

LYON, D. Pós-modernidade. São Paulo: Paulus, 1996.

LYOTARD, J.-F. A condição pós-moderna. Rio de Janeiro: José Olympio, 2009.

NOGUEIRA, A. 0 conceito ideológico do Direito na Escola do Recife. Fortaleza: EdBNB, 1980.

OLIVEIRA, M. A Filosofia na crise da modernidade. São Paulo: Loyola, 1989.

PAIM, A. A Filosofia da Escola do Recife. Rio de Janeiro: Saga, 1966.

ROMERO, S. Introdução à Doutrina contra doutrina. São Paulo: Companhia das Letras, 2001.

VATIMO, G. Fim da modernidade. Niilismo e hermenêutica na cultura pós-moderna. São Paulo: Martins Fontes, 1996.

Recebido em: 10/2/2021

Aprovado em: 27/4/2021

\section{Francisco José da Silva}

Doutor em Filosofia pela Universidade Federal do Ceará (UFC, 2020). Atualmente é Pesquisador e Professor Adjunto do curso de Filosofia do Instituto Interdisciplinar de Sociedade, Cultura e Arte (IISCA) da Universidade Federal do Cariri (UFCA), coordenador de subprojeto Pibid Filosofia (2020). Tem experiência em gestão, tendo sido Coordenador do curso de Filosofia UFCA (2013-2014), Coordenador do Núcleo de Línguas e Culturas Estrangeiras (2014-2015) e da Coordenadoria de Diversidade Cultural da Procult (2015-2016). Membro do Conselho editorial da Revista Araripe de Filosofia (UFCA). Membro da Comissão de Ética da UFCA. Tem experiência na área de Filosofia, com ênfase em Filosofia Alemã, atuando principalmente nos seguintes temas: Idealismo Alemão (Hegel), Dialética e Hermenêutica (Schleiermacher), Filosofia da Religião e Filosofia Intercultural (Raul Fornet-Betancourt). Também tem interesse no pensamento filosófico brasileiro (Farias Brito). Membro da Sociedade Hegel Brasileira (SHB) e da Associação Latinoamericana de Filosofia Intercultural (ALAFI). 